\title{
Epidural, paravertebral and bilateral psoas abscess after lumbar acupuncture
}

\author{
André Rosa Alexandre, Pedro Raimundo
}

Departamento de Medicina Interna e Medicina Intensiva, Hospital da Luz Lisboa, Lisboa, Portugal

\section{Correspondence to}

Dr Pedro Raimundo,

p_oliveiraraimundo@yahoo.com

Accepted 1 November 2018

\section{DESCRIPTION}

A 52-year-old Caucasian woman presented to the emergency department with worsening of her chronic low back pain along with de novo functional impotence of left lower limb with 1-week duration. She had been submitted to lumbar acupuncture for pain relief 2 weeks before presentation.

The patient was previously healthy except for her mechanical chronic back pain. She was chronically medicated with non-steroidal inflammatory drugs with partial relief. She had no relevant family history.

On clinical examination, she was conscious and reactive, afebrile and haemodynamically stable. She was eupnoeic and her oxygen saturation on pulse oximetry was 99\%. Her lumbar spine was tender to palpation. A mass with purulent discharge was found on the inner side of her right thigh and the neurological examination revealed a slight proximal strength deficit (grade 4 in 5) on her left lower limb. The remainder of the physical examination was unremarkable.

A leucocytosis $\left(18.2 \times 10^{9} / \mathrm{L}\right)$ with neutrophilia $(87 \%)$ was found along with elevated $\mathrm{C}$ reactive protein $(25 \mathrm{mg} / \mathrm{dL})$, reduced haemoglobin with normocytic normochromic anaemia $(8.5 \mathrm{~g} / \mathrm{dL})$ and thrombocytosis $\left(872 \times 10^{9} / \mathrm{L}\right)$. The renal and hepatic functions were within normal range.

A lumbosacral magnetic resonance showed an infectious involvement of the left facet joint between L4 and L5 vertebrae (figure 1) due to direct inoculation by the acupuncture needle. This joint infection was complicated by an extensive epidural abscess from T12 to S1 vertebral level (figure 1) with a large bilateral spill to psoas and

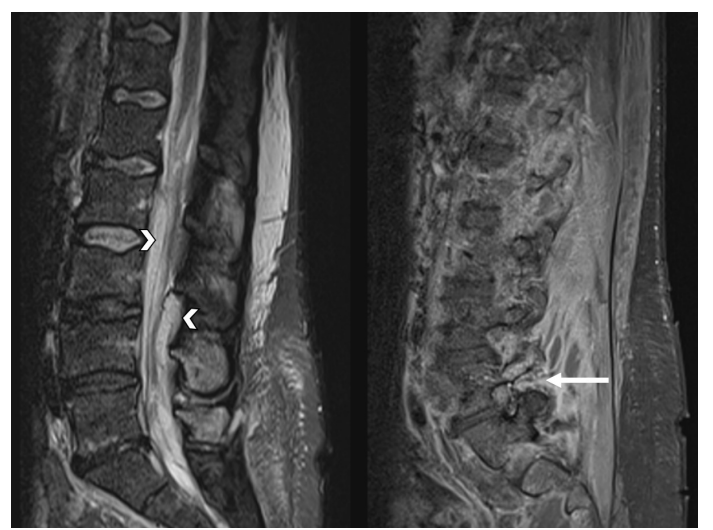

Figure 1 Lumbosacral magnetic resonance showing left facet joint infection between L4 and L5 vertebrae (arrow) and an extensive epidural abscess (arrowhead) from T12 to S1 vertebral level.

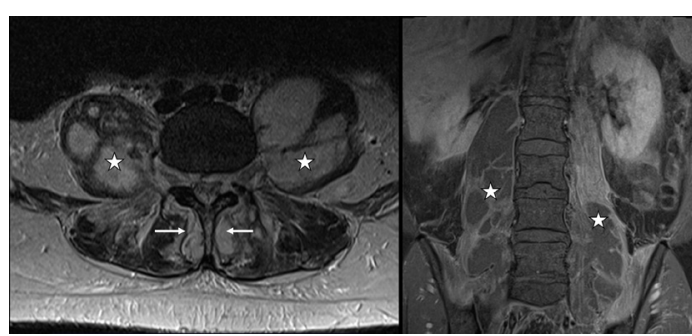

Figure 2 Lumbosacral magnetic resonance showing the presence of bilateral paravertebral (arrows) and psoas abscesses (stars).

paravertebral abscesses (figure 2). There was also evidence of purulent discharge tracking down from the right psoas abscess to the skin of the inner face of the patient's right thigh along the iliopsoas tendon sheet. Blood and aspirate cultures from the abscesses were positive for methicillin-resistant Staphylococcus aureus. Both transthoracic and transoesophageal echocardiograms excluded the presence of infective endocarditis.

After being assessed by the Neurosurgery Team, the patient was admitted to the ward. She was treated conservatively with percutaneous drainage of the abscesses along with a 6-week course of intravenous vancomycin and an additional 2 weeks of oral linezolid after hospital discharge.

She made a full recovery and has been followed up in our outpatient clinic for 2 years without further events.

This case highlights the importance of correctly treating chronic back pain. The prevalence of this condition can reach as high as $25.4 \%$ of the adult population and increases linearly from the third decade of life on, being more frequent in women. ${ }^{1}$ Failure in controlling back pain may lead patients to recur to forms of complementary and alternative medicine without evidence-based results to this indication. Acupuncture is one of these alternatives,

Learning points

- Chronic low back pain is a prevalent problem that demands correct treatment.

- Patients without symptomatic control tend to recur to complementary and alternative medicine mostly without evidencebased indication.

- Acupuncture, one of most commonly used complementary and alternative medicine techniques, has rare but potentially serious complications. 
and although generally assumed as safe and free of associated risks, may lead to serious complications. Our intention with this case report is to raise awareness of those risks. Deep infections, like the one we report here, are perfect examples. As far as we know, this is the first case reported in the literature of epidural abscess, and only the third of bilateral psoas abscesses, complicating an acupuncture procedure. ${ }^{23}$

Contributors ARA wrote the body of the article and learning points. PR reviewed the whole article.

Funding The authors have not declared a specific grant for this research from any funding agency in the public, commercial or not-for-profit sectors.
Competing interests None declared.

Patient consent Obtained.

Provenance and peer review Not commissioned; externally peer reviewed.

\section{REFERENCES}

1 Meucci RD, Fassa AG, Faria NMX. Prevalence of chronic low back pain: systematic review. Revista de Saúde Pública 2015;49:1-10.

2 He C, Wang T, Gu Y, et al. Unusual case of pyogenic spondylodiscitis, vertebral osteomyelitis and bilateral psoas abscesses after acupuncture: diagnosis and treatment with interventional management. Acupunct Med 2015;33:154-7.

3 Garcia AA, Venkataramani A. Bilateral psoas abscesses following acupuncture. West $\mathrm{J}$ Med 1994;161:90

Copyright 2018 BMJ Publishing Group. All rights reserved. For permission to reuse any of this content visit https://www.bmj.com/company/products-services/rights-and-licensing/permissions/

BMJ Case Report Fellows may re-use this article for personal use and teaching without any further permission.

Become a Fellow of BMJ Case Reports today and you can:

- Submit as many cases as you like

- Enjoy fast sympathetic peer review and rapid publication of accepted articles

Access all the published articles

Re-use any of the published material for personal use and teaching without further permission

For information on Institutional Fellowships contact consortiasales@bmjgroup.com

Visit casereports.bmj.com for more articles like this and to become a Fellow 